\title{
Intracranial subdural hematoma following dural puncture in a parturient with HELLP syndrome
}

\author{
[Hématome sous-dural intracrânien post-ponction durale chez une parturiente \\ atteinte du syndrome HELLP]
}

Tiberiu Ezri MD, * Ezzat Abouleish MD, $†$ Charles Lee MD, $†$ Shmuel Evron MD*

Purpose: To present a case of postpartum bilateral intracranial subdural hematoma after dural puncture during attempted epidural analgesia for labour.

Clinical features: This complication occurred following accidental dural puncture in a parturient with thrombocytopenia $\left(99,000 \cdot \mu \mathrm{L}^{-1}\right)$ who subsequently developed the syndrome of hemolysis, elevated liver enzymes and low platelets. On the first postoperative day, postdural puncture headache (PDPH) developed. An epidural blood patch (EBP) was deferred to the third postoperative day because of a platelet count of $21,000 \cdot \mu \mathrm{L}^{-1}$. However, the headache intensified from a typical PDPH to one which was not posturally related. A second EBP was abandoned after the injection of $5 \mathrm{~mL}$ of blood because of increasing headache during the procedure. Magnetic resonance imaging revealed bilateral temporal subdural hematomas. The patient was managed conservatively and discharged home without any sequelae.

Conclusion: It is conceivable that thrombocytopenia together with possible abnormal platelet function increased the risk of subdural hematoma. Alternative diagnoses to PDPH should be considered whenever headache is not posturally related.

Objectif : Présenter un cas d'hématome sous-dural intracrânien bilatéral du postpartum à la suite d'une ponction durale pendant l'administration d'analgésie épidurale pour le travail obstétrical.

Éléments cliniques : La complication est survenue après une ponction durale chez une parturiente qui présentait une thrombocytopénie (99 000 $\mu \mathrm{L}^{-1}$ ) et chez qui s'est ensuite développé un syndrome d'hémolyse, d'enzymes hépatiques élevés et d'un faible taux de plaquettes. Au premier jour postopératoire, la patiente a subi des céphalées post-ponction durale (CPPD). Un colmatage sanguin épidural (CSE) a été reporté au troisième jour postopératoire, étant donné la numération plaquettaire à $21000 \cdot \mu L^{-1}$. Cependant, les céphalées ont augmenté jusqu'à n'avoir plus de lien avec la position du corps. Un second
CSE a été abandonné après l'injection de $5 \mathrm{~mL}$ de sang, l'intervention augmentant la céphalée. L'imagerie par résonance magnétique a révélé des hématomes sous-duraux, temporaux, bilatéraux. La patiente a reçu un traitement conservateur et a quitté l'hôpital sans séquelles.

Conclusion : On peut imaginer qu'une thrombocytopénie combinée à une dysfonction plaquettaire possible pourra accroitre le risque d'hématome sous-dural. II faut envisager un autre diagnostic que la CPPD chaque fois que la position n'est pas en cause.

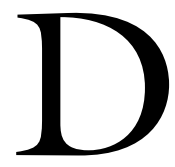

URAL puncture occurring during spinal anesthesia or unintentionally during epidural administration may cause postdural puncture headache (PDPH) independent of the needle size used. ${ }^{1}$ Intracranial hematoma is a rare consequence of accidental dural puncture. Cerebrospinal fluid leakage from the punctured dura may reduce the intracranial pressure leading to stretch and tearing of subdural veins ${ }^{2}$ even in healthy individuals. Contributory factors in the development of this pathology could be Valsalva maneuver, ${ }^{3}$ brain atrophy ${ }^{4}$ or thrombocytopenia together with possible platelet dysfunction as occurs in severe preeclamptic parturients. ${ }^{5}$ The present case report emphasizes the need for careful assessment and consideration of the influence of platelet pathology as a predisposing factor.

\section{Case report}

A 29 -yr-old primiparous (height $170 \mathrm{~cm}$, weight $80 \mathrm{~kg}$ ) presented at the delivery ward at 36-week gestation with severe preeclamptic toxemia. Blood pressure was

From the Departments of Anesthesiology, Wolfson Medical Center, ${ }^{*}$ Holon and Sackler Faculty of Medicine, Tel-Aviv University, Israel; and the University of Texas Medical School, $\dagger$ Houston, Texas, USA.

Address correspondence to: Dr. Tiberiu Ezri, Department of Anesthesiology, the Edith Wolfson Medical Center, Holon - Israel. Phone:

97235028 229; Fax: 97235028 228; E-mail: etb@netvision.net.il

Accepted for publication January 14, 2002

Revision accepted July 10, 2002. 
$165 / 115 \mathrm{mmHg}$ on three repeated measurements. She had peripheral edema +3 , proteinuria $6 \mathrm{~g} \cdot \mathrm{day}^{-1}$ and oliguria. She had no headache, abdominal pain or visual disturbances. Peripheral reflexes were mildly brisk, platelet count $99,000 \cdot \mu \mathrm{L}^{-1}$, coagulation, serum creatinine and liver function tests were within normal ranges. After magnesium sulfate and hydralazine treatment was initiated, labour was induced with oxytocin. Epidural analgesia was attempted at $3 \mathrm{~cm}$ cervical dilatation. The needle (Tuohy No 18G) insertion at the L2-3 level proved difficult, and an accidental dural puncture occurred. Repeated doses of iv meperidine were used to relieve labour pain. During the first $24 \mathrm{hr}$, blood pressure was well controlled, urine output improved $\left(1 \mathrm{~mL} \cdot \mathrm{kg}^{-1} \cdot \mathrm{hr}^{-1}\right)$, clotting function and liver enzymes were within normal ranges. Twenty four hours after admission (at cervical dilatation of $5 \mathrm{~cm}$ ), an epidural was successfully inserted at the same interspace (L2-3). One hour after the successful epidural, uneventful Cesarean delivery was performed under epidural anesthesia because of an alarming fetal heart rate tracing. One hour postoperatively signs of hemolysis, elevated liver enzymes and low platelets (HELLP) syndrome developed: platelet count: $60,000 \cdot \mu \mathrm{L}^{-1}$, serum bilirubin $2 \mathrm{mg} \cdot \mathrm{dL}^{-1}$, hemoglobinuria +3 , positive Coombs test, and elevated ALT 250 $\mathrm{IU} \cdot \mathrm{L}^{-1}$ and AST $350 \mathrm{IU} \cdot \mathrm{L}^{-1}$. Prothrombin time was 12 sec, partial thromboplastin time $24 \mathrm{sec}$ and the international normalized ratio 1.1. The hemoglobin decreased from $12 \mathrm{mg} \cdot \mathrm{dL}^{-1}$ on admission to $9.5 \mathrm{mg} \cdot \mathrm{dL}^{-1}$ on the third day after admission. Fibrinogen level was 250 $\mathrm{mg} \cdot \mathrm{dL}^{-1}$ and fibrinogen split products were normal. Postoperatively, patient controlled epidural analgesia with bupivacaine $0.125 \%$ was used. Non-steroidal antiinflammatory drugs were not administered.

On the first postoperative day, the patient developed mild PDPH which was treated with $i v$ hydration and bed rest. Epidural blood patch (EBP) was deferred because of thrombocytopenia $\left(21,100 \cdot \mu \mathrm{L}^{-1}\right)$. EBP was performed on the third postoperative day when the PDPH worsened and platelet count was $150,000 \cdot \mu \mathrm{L}^{-1}$. Fifteen millilitres of autologus blood were injected at the L2-3 level. No back pain or headache were encountered during the EBP. The patient was discharged home with a persistent mild headache but was readmitted the next day for a constant and intense headache unrelated to posture. Upon her readmission to hospital, EBP was repeated hoping it would be efficient this time. It was performed at the same spinal interspace (L2-3) but was abandoned after $5 \mathrm{~mL}$ of blood injection because of increasingly severe headache during the procedure. This led to a reconsideration of the diagnosis and a neurologist was consulted. A magnetic resonance

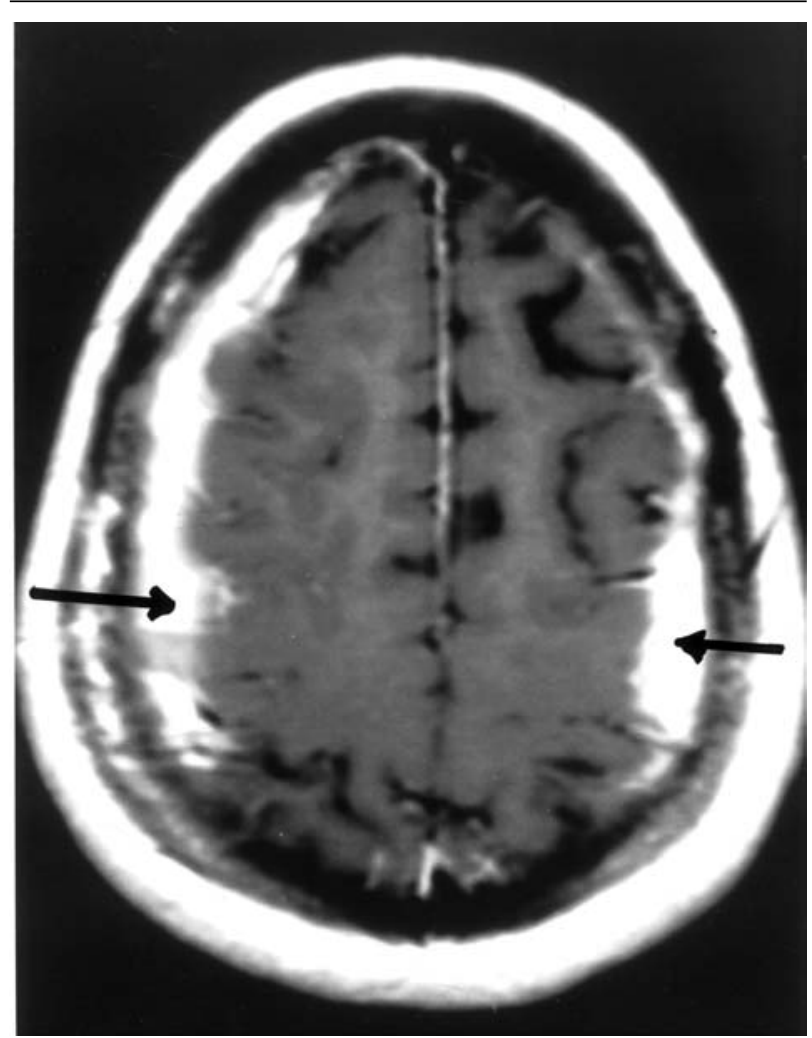

FIGURE Brain magnetic resonance imaging showing bilateral temporal subdural hematomas (arrows).

imaging (MRI) investigation revealed bilateral temporal subdural hematomas (Figure).

Besides the headache, there were no other neurologic abnormalities. The patient was managed conservatively and on the sixth postoperative day a follow-up MRI showed that the hematoma resolved. On the seventh postoperative day she was discharged home without sequelae. It is worth mentioning that several differential diagnoses of severe headache were not ruled out, including tension headache or migraine, although they were considered unlikely because of the acute onset and the lack of past history of such conditions.

\section{Discussion}

This case illustrates the problematic of diagnosing the origin of a headache in the peripartum period. The differential diagnosis includes PDPH, preeclamptic toxemia, migraine, simple tension headache, subdural or subarachnoid hemorrhage, cortical vein thrombosis and meningitis. ${ }^{7}$ 
Knowing that dural puncture occurred and the headache had a postural component, it was assumed that the most likely diagnosis in our patient was PDPH. The frequency and severity of PDPH are proportionate to the size of the needle although PDPH may follow the use of any size needle. ${ }^{1}$ Significant lumbar cerebro-spinal fluid (CSF) leakage results in low intracranial pressure. This may lead to traction and distortion of thin-walled dural blood vessels, ${ }^{2}$ but rarely leads to intracranial hematoma. A typical PDPH is exacerbated in the upright position and relieved by the horizontal position. Absence of a postural component should lead to consideration of alternative intracranial pathology. The neurology service should be consulted if the diagnosis is in doubt. It is well known that PDPH may mimic or unmask pre-existing neurological complications. ${ }^{8,9}$

Subdural hematoma may develop rarely after spinal block even with the use of a small caliber needle, ${ }^{10-13}$ or with accidental dural puncture with a Tuohy needle. ${ }^{14-17}$ The incidence of subarachnoid hemorrhage in pregnancy is only $1: 10,000$ but is associated with high maternal mortality. ${ }^{18}$ Predisposing conditions leading to excessive CSF leakage may include expulsive efforts (Valsalva maneuver) during labour ${ }^{3}$ and cerebral atrophy. ${ }^{4}$ Several other factors may increase the risk of intracranial bleeding: severe hypertension and thrombocytopenia as was the case in our patient. In addition, the patient may have had platelet dysfuction associated with preeclampsia and HELLP syndrome. Although platelet dysfunction was not diagnosed in the present case, it has been reported previously. ${ }^{5,6,19}$ HELLP syndrome which was diagnosed in our patient is known to develop in $10 \%$ of pregnancies complicated with severe preeclampsia. In a study of 33 patients with HELLP syndrome ${ }^{20}$ epidural anesthesia was performed in eight parturients with no apparent complications. In another report, epidural bleeding has been associated with epidural anesthesia in patients with HELLP syndrome. ${ }^{21}$ Furthermore, disseminated intravascular coagulation may occur with HELLP syndrome in up to $39 \%$ of patients. $^{22}$

Compared to PDPH, the headache of intracranial hematoma is associated with focal neurological abnormalities and signs of increased intracranial pressure (ICP) such as confusion and vomiting. Seizures induced by an increased ICP may be misinterpreted as eclampsia. ${ }^{23}$

The diagnosis of intracranial hematoma is based on clinical judgment, computed tomography (CT) and MRI. A plain CT scan unlike contrast CT or MRI, may be misleading during the first three weeks because the hematoma has the same radiological density as the brain and this may delay diagnosis. ${ }^{24}$ Treatment may be surgical or conservative. ${ }^{4,13}$ Our patient did not require surgery because of the small size of the subdural hematomas and improvement of the neurological signs. Conservative treatment is in agreement with two previously published studies. ${ }^{10,23}$ EBP may enhance the suspicion of intracranial hematoma if the pain is not relieved or worsens during the procedure, since injection of liquids into the epidural space can cause a sudden increase of CSF pressure. ${ }^{25}$ In retrospect, the decision to attempt a second blood patch in our patient was unwise.

Vasopressor agent administration (i.e., ephedrine) may cause swings in blood pressure and facilitate rupture of intracranial aneurysms or arteriovenous malformations (AVM). Such ruptures may occur spontaneously during labour with an incidence of one to five per 10,000 pregnancies, ${ }^{26} 77 \%$ of the ruptures secondary to aneuryms and $23 \%$ to AVM. ${ }^{27}$ Other causes of spontaneous subarachoid hemorrhage during pregnancy include: anticoagulant therapy, placental abruption with disseminated intravascular coagulopathy, eclampsia, etc. ${ }^{28}$

In summary, we present a parturient with bilateral intracranial subdural hematomas following inadvertent dural puncture and thrombocytopenia due to HELLP syndrome. It is conceivable that thrombocytopenia together with possible abnormal platelet function increased the risk of this complication in this preeclamptic woman. Alternative diagnosis to $\mathrm{PDPH}$ should be considered if headache is not posturally related. Scrupulous attention should be accorded to the investigation of intracranial bleeding by use of contrast CT or MRI when the headache, recurring after the first EBP, becomes atypical, intense and unrelated to posture before a second EBP is considered.

\section{References}

1 Weeks SK. Postpartum headache. In: Chestnut DH (Ed.). $2^{\text {nd }}$ ed. Obstetric Anesthesia. Principles and Practice. St. Louis: Mosby, 1999: 621-35.

2 Russel IF. Postpartum neurological problems. In: Russels IF, Lyons G, (Eds.). Clinical Problems in Obstetrics Anaesthesia. London: Chapman and Hall Medical, 1997: 149-60.

3 Newrick P, Read D. Subdural haematoma as a complication of spinal anaesthetic. Br Med J 1982; 285: 341-2.

4 Cohen JE, Godes J, Morales B. Postpartum bilateral subdural hematomas following spinal anesthesia: case report. Surg Neurol 1997; 47: 6-8.

5 Burrows RF, Hunter DJS, Andrew M, Kelton JG. A prospective study investigating the mechanism of 
thrombocytopenia in preeclampsia. Obstet Gynecol 1987; 70: 334-8.

6 Kelton JG, Hunter DJS, Neame PB. A platelet function defect in preeclam. Obstet Gynecol 1985; 65: 107-9.

7 Berger CW, Crosby ET, Grodecki W. North American survey of the management of dural puncture occurring during labour epidural analgesia. Can J Anaesth 1998; 45: 110-4.

8 Alfery DD, Marsh ML, Shapiro HM. Post-spinal headache or intracranial tumor after obstetric anesthesia. Anesthesiology 1979; 51: 92-4.

9 Rabme ES, Green D. Chronic subdural hematoma in adolescence and early adulthood. Hospital records disclose a surprising frequency and emphasize the value of ventriculography in differential diagnosis. JAMA 1961; 176: 424-6.

10 Vos PE, de Boer WA, Wurzer JAL, van Gijn J. Subdural hematoma after lumbar puncture: two case reports and review of the literature. Clin Neurol Neurosurg 1991; 93: 127-32.

11 Thorsen $G$. Neurological complications after spinal anaesthesia and results from 2495 follow-up cases. Acta Chir Scand 1947; 95(Suppl 121): 1-272.

12 Johnsson LO, Einarsson P, Olsson GL. Subdural haematoma and spinal anaesthesia. A case report and an incidence study. Anaesthesia 1983; 38: 144-6.

13 Akpek EA, Karaaslan D, Erol E, Caner H, Kayhan Z. Chronic subdural haematoma following caesarean section under spinal anaesthesia. Anaesth Intensive Care 1999; 27: 206-8.

14 Dobrmann PJ, Elrick WL, Siu KH. Intracranial subdural hematoma after lumbar myelography. Neurosurgery 1983; 12: 694-6.

15 Edelman JD, Wingard DW. Subdural hematomas after lumbar dural puncture. Anesthesiology 1980; 52: 166-7.

16 Gupta SR, Nabeedy MH, Rubino FA. Cranial subdural hematoma following lumbar myelography. Comput Radiol 1985; 9: 129-31.

17 Dunn DW. Acute subdural hematoma after subdural puncture. Am J Dis Child 1982; 136: 371-2.

18 Yih PSW, Cheong KF. Anaesthesia for caesarean section in a patient with an intracranial arteriovenous malformation. Anaesth Intensive Care 1999; 27: 66-8.

19 Ramanathan J, Sibai BM, Vu T, Chauban D. Correlation between bleeding times and platelet counts in women with preeclampsia undergoing cesarean section. Anesthesiology 1989; 71: 188-91.

20 Crosby ET. Obstetrical anaesthesia for patients with the syndrome of haemolysis, elevated liver enzymes and low platelets. Can J Anaesth 1991; 38: 227-33.

21 Sibai BM, Taslimi MM, El-Nazer A, Amon E, Mabie $B C$, Ryan GM. Maternal-perinatal outcome associated with the syndrome of hemolysis, elevated liver enzymes, and low platelets in severe preeclampsiaeclampsia. Am J Obstet Gynecol 1986; 155: 501-9.

22 Isler CM, Rinehart BK, Terrone DA, Martin RW, Magann EF, Martin JN Jr. Maternal mortality associated with HELLP (hemolysis, elevated liver enzymes, and low platelets) syndrome. Am J Obstet Gynecol 1999; 181: 924-8.

23 Vaughan DJA, Stirrup CA, Robinson PN. Cranial subdural haematoma associated with dural puncture in labour. Br J Anaesth 2000; 84: 518-20.

24 Wyble SW, Baybi D, Webre D, Viswanathan S. Bilateral subdural hematomas after dural puncture: delayed diagnosis after false negative computed tomography scan without contrast. Reg Anesth 1992; 17: 52-3.

25 Ramsay $M$, Roberts $C$. Epidural injection does cause an increase in CSF pressure (Letter). Anesth Analg 1991; 73: 668-76.

26 Wilterdink JL, Feldmann E. Cerebral hemorrhage. In: Devinsky O, Feldmann E, Hainline B (Eds.). Neurologic Complications of Pregnancy. New York: Raven Press, 1994: 13-23.

27 Dias MS, Sekhar LN. Intracranial hemorrhage from aneurysms and arteriovenous malformations during pregnancy and the puerperium. Neurosurgery 1990; 27: 855-66.

28 Donaldson JO. Neurology of Pregnancy, $2^{\text {nd }}$ ed. London: WB Saunders, 1989: 137-40. 